\title{
EVALUACIÓN DE RESIDUOS AGRÍCOLAS COMO SUSTRATO PARA LA PRODUCCIÓN DE Pleurotus ostreatus ${ }^{1}$
}

\author{
RUBY LEONOR RIVERA OMEN², CARLOS AUGUSTO MARTÍNEZ \\ MAMIÁN ${ }^{3}$, SANDRA MORALES VELASCO ${ }^{4}$
}

Recibido el 26 de abril de 2013 y aprobado el 16 de junio de 2013

\section{RESUMEN}

El cultivo de los hongos del género Pleurotus sp. es de importancia debido a que producen proteínas de alta calidad sobre un sustrato que consiste en materiales de desecho de carácter lignocelulósico. El objetivo fue evaluar el uso de residuos agrícolas: cáscara de papa, plátano y bagazo de caña, como una alternativa proteica en el corregimiento de Llacuanas municipio de Almaguer (Cauca). El diseño experimental fue completamente al azar, con cuatro tratamientos y cinco repeticiones por tratamiento, donde se tuvieron en cuenta variables físicas (color y textura); y de producción (Colonización, peso y diámetro). El análisis de varianza mostro diferencias estadísticas significativas para peso y diámetro; y la prueba post hoc de Duncan, evidenció que los mejores tratamientos fueron 1 y 2 (Bagazo de caña, cascara de plátano, salvado de maíz y cal agrícola), sustratos constituidos por carbohidratos estructurales que favorecen el desarrollo del hongo.

\section{PALABRAS CLAVE}

Hongos, semilla, inoculación, carbohidratos estructurales.

\section{EVALUATION OF AGRICULTURAL WASTE AS SUBSTRATE FOR THE PRODUCTION OF Pleurotus ostreatus}

\section{ABSTRACT}

The cultivation of fungi of the genus Pleurotus $s p$. is of importance because they produce high quality protein on a substrate consisting of lignocellulosic IN waste materials. The objective was to evaluate the use of agricultural residues: potato peels, banana and sugarcane pulp, as an alternative protein in the village of Llacuanas, municipality of Almaguer (Cauca). The experimental design was completely randomized with four treatments and five replicates per treatment in which physical variables (color and texture) and production (Colonization, weight and diameter) were considered. The analysis of variance showed statistically significant differences for weight and diameter; the Duncan post hoc test showed that the best treatments were 1 and 2 (sugarcane pulp, banana peel, corn bran and agricultural lime), substrates consisting of structural carbohydrates that promote the growth of the mushroom.

\section{KEYWORDS}

Mushrooms, seed, inoculation, structural carbohydrates. 


\section{INTRODUCCIÓN}

El cultivo de setas comestibles Pleurotus sobre sustratos lignocelulósicos es una buena alternativa para producir alimentos, por lo que son considerados como una fuente barata de proteína y las setas convierten los desechos agrícolas en alimentos. La mayoría pueden ser generados en un corto período de tiempo a bajo costo y en áreas reducidas. Además, el desarrollo del cultivo a pequeña escala en países en desarrollo necesita una tecnología sencilla, de condiciones poco sofisticadas. Después del proceso de cultivo y la cosecha de las setas, el sustrato remanente es aprovechable como abono orgánico, por su alto contenido en nitrógeno, fósforo y potasio (García-Oduardo et al., 2011).

La importancia de esta investigación se fundamenta en la producción de hongos comestibles del género Pleurotus ostreatus a partir de residuos agrícolas, de tal forma que puedan ser fuente de alimentación que permitan disminuir los índices de desnutrición, siendo por tanto, alternativa de seguridad alimentaria en las áreas rurales del municipio de Almaguer, el cual presenta altos índices de morbilidad y mortalidad ocasionados por la desnutrición y la mala alimentación, problemas que afronta la comunidad del corregimiento de Llacuanas, en la que se observan casos de deterioro en la calidad de vida, reflejados en el desarrollo físico y psíquico, poniendo en peligro el desarrollo social, además los procesos de injusticia social y económica determinan que niños, adultos y ancianos enfermen, sufran hambre y mueran prematuramente (Municipio de Almaguer - POT, 2004 2016).

La agricultura se ha visto desplazada por la siembra de cultivos de uso ilícitos; unido a esto la carencia en manejo de residuos sólidos ha generado focos de contaminación orgánica, aumentando la presencia de plagas (roedores, moscas, entre otros) acrecentando los impactos sobre el suelo y por ende afectando la productividad de los mismos (Municipio de Almaguer - POT, 2004 - 2016); de lo anterior surge la necesidad de generar alternativas para evaluar residuos agrícolas (cáscara de papa, bagazo de caña, cáscara de plátano) como sustrato para la producción de Pleurotus ostreatus, cuantificando los residuos orgánicos de los restaurantes de la localidad.

El uso de Pleurotus ostreatus tiene la ventaja de ser un complemento alimenticio por su valor nutricional, ya que contiene entre $57 \%$ y $61 \%$ de carbohidratos, $26 \%$ de proteína, $11,9 \%$ de fibra y $0,9 \%$ a $1,8 \%$ de grasas con base a su peso seco, además posee vitaminas como la niacina, tiamina (B1), vitamina B12, vitamina C o ácido ascórbico y se le han detectado minerales como potasio, fósforo y calcio (Barros et al., 2008;Guillamónet al., 2010). Esta especie es cosmopolita y crece saprofíticamente en ambientes naturales sobre troncos de árboles caídos y otras plantas leñosas en descomposición; es un hongo semianaeróbico que soporta un $32 \%$ de $\mathrm{CO}_{2}$ y fija el nitrógeno atmosférico, produce grandes cantidades de proteína de alta calidad sobre sustratos que están compuestos de materiales residuales, siendo más eficiente sobre los lignocelulósicos, como pajas, cascarillas de cereales, bagazos, tusas, pastos, cáscaras, entre otros (Soto, 2004). 


\section{MATERIALES Y MÉTODO}

La propuesta se desarrolló en el corregimiento de Llacuanas, suroccidente del municipio de Almaguer (Cauca), a una temperatura promedio de $17^{\circ} \mathrm{C}$ y a 1500 msnm (Municipio de Almaguer - POT, 2004 - 2016).

\section{Preparación del sustrato e inoculación}

Recolección de residuos. Los residuos orgánicos se colectaron los días domingos en los restaurantes del corregimiento de Llacuanas (día en que la comunidad se prepara para las actividades de mercado local). Los residuos fueron: cáscaras de plátano y papa. Teniendo en cuenta que la región se caracteriza por la producción de panela, el bagazo de caña fue recogido en los trapiches paneleros de las veredas aledañas al corregimiento.

Desinfección del sustrato. Los sustratos de cáscara de plátano y papa fueron pesados individualmente, seguidamente se seleccionaron y clasificaron conforme a su estado de madurez y condiciones fitosanitarias. Posteriormente se realizó la desinfección con hipoclorito de sodio a 20 ppm durante diez minutos; consecutivamente se lavó con agua potable y se secó a temperatura ambiente hasta obtener una humedad del $10 \%$, finalmente se cortaron en partículas de $2 \mathrm{~cm}$.

El bagazo caña se cortó en partes de aproximadamente $2 \mathrm{~cm}$, seguido de una inmersión en agua a temperatura ambiente durante 48 horas, cambiándola cada 12 horas, eliminando de esta manera los azúcares que quedan del proceso de la molienda; posteriormente se efectuó la desinfección con hipoclorito a 20 ppm. El salvado de maíz se desinfectó agregándole tres veces agua hirviendo, con el fin de evitar la desintegración de las estructuras nutricionales, como carbohidratos y proteínas (Fernández, 2004).

Pasteurización del sustrato. La pasteurizaron se realizó solo a los residuos de plátano, papa y bagazo de caña; estos se procesaron por separado a $80^{\circ} \mathrm{C}$ durante una hora, con el objetivo de eliminar microorganismos que puedan afectar el cultivo (Cardona, 2005).

Área de trabajo. La fase experimental se llevó a cabo en un cuarto cerrado con paredes de ladrillo, tejas en fibrocemento y piso de cemento. Las dimensiones fueron: $3 \mathrm{~m} \times 3 \mathrm{~m}$ y una altura de $2,50 \mathrm{~m}$. Se lavaron las paredes y el piso con hipoclorito de sodio a 20 ppm, se flameó toda la habitación y finalmente se aplicó cal en el piso.

Para obtener las condiciones requeridas por el Pleurotus, se cubrió la ventana con polisombra al $70 \%$, manteniendo condiciones de luz y temperatura; para asegurar la humedad adecuada se realizaron riegos con una frecuencia de tres veces al día. Las variables fueron monitoreadas diariamente con un termohigrómetro.

Inoculación del hongo. Se desinfectó el mesón con hipoclorito a 20 ppm, las puertas fueron cerradas para evitar corrientes de aire, se escurrió el sustrato para evitar contaminarlo y se procedió a pesar los sustratos por tratamientos aplicando a cada bolsa $2 \%$ de cal agrícola, $23 \%$ de salvado de maíz y 5\% del peso húmedo del sustrato en semilla. 
Después de pesar el sustrato, se mezcló homogéneamente la semilla, la cal y el salvado en un recipiente, se colocó dentro de la malla (para crecimiento y desarrollo del hongo) y posteriormente cada malla se depositó en una bolsa de polietileno negra con el fin de brindar las condiciones adecuadas para la incubación del micelio, la cual fue retirada una vez el micelio cubrió totalmente el sustrato.

Fructificación. Se retiró la bolsa negra para dar lugar al crecimiento de los primordios, con una temperatura de 18 a $19^{\circ} \mathrm{C}$ y 80 a $85 \%$ de humedad relativa. Estas condiciones se consiguieron humedeciendo el cuarto con agua potable mediante 2 a 4 microaspersiones por día.

Cosecha. Los hongos se cosecharon cuando su parte superior estuvo plana (momento en el cual alcanza su máximo crecimiento), cortando por la base del tallo en el punto de unión con el sustrato.

Tratamientos. Se conformaron teniendo en cuenta los requerimientos nutricionales del hongo. Es de aclarar que dadas las condiciones de la zona donde se realizó el experimento, no se realizaron análisis proximales de los tratamientos formulados. El diseño experimental que se utilizó fue completamente al azar, con cuatro tratamientos y cinco repeticiones por tratamiento. Los bloques fueron separados a $70 \mathrm{~cm}$ para dar espacio al crecimiento de los carpóforos y facilitar su recolección.

Tabla 1. Tratamientos del diseño experimental

\begin{tabular}{|c|c|c|}
\hline Tratamiento & Sustrato & Porcentaje \\
\hline T1 & $\begin{array}{c}\text { Bagazo de caña panelera + salvado } \\
\text { de maíz + cal agrícola }\end{array}$ & $75 \%, 23 \%$ y $2 \%$ \\
\hline T2 & $\begin{array}{c}\text { Bagazo de caña panelera + cáscara } \\
\text { de plátano + cal agrícola + salvado } \\
\text { de maiz }\end{array}$ & $38 \%, 37 \%, 2 \%$ y $23 \%$ \\
\hline T3 & $\begin{array}{c}\text { Bagazo de caña panelera + cáscara } \\
\text { de papa + salvado de maíz + cal } \\
\text { agrícola }\end{array}$ & $38 \%, 37 \%, 23 \%$ y $2 \%$ \\
\hline T4 & $\begin{array}{c}\text { Bagazo de caña panelera + cáscara } \\
\text { de plátano + cáscara de papa + } \\
\text { salvado de maíz + cal agrícola }\end{array}$ & $37 \%, 19 \%, 19 \%, 23 \%$ y $2 \%$ \\
\hline
\end{tabular}

Las variables tenidas en cuenta fueron: físicas y de producción.

\section{Variables físicas}

Textura. Durante la recolección de cada seta y mediante tacto directo se clasificaron como textura carnosa y deshidratada.

Color. Teniendo en cuenta la escala de colores realizada por Romero, Rodríguez y Pérez (s.f.), se clasificaron las setas por observación directa.

\section{Variables de producción}

Porcentaje de colonización. Se dejaron transcurrir 16 días para retirar las bolsas de polietileno negras de cada uno de los tratamientos. Mediante observación directa se cuantificó el porcentaje de colonización del micelio del hongo en la totalidad de la malla. 


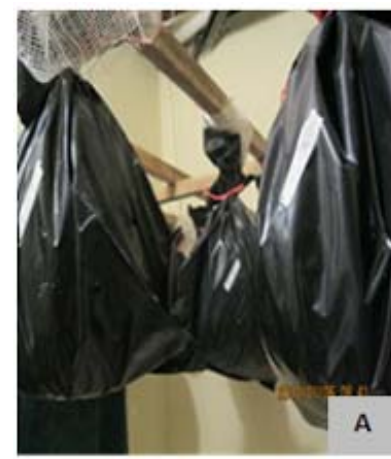

A: Incubación.

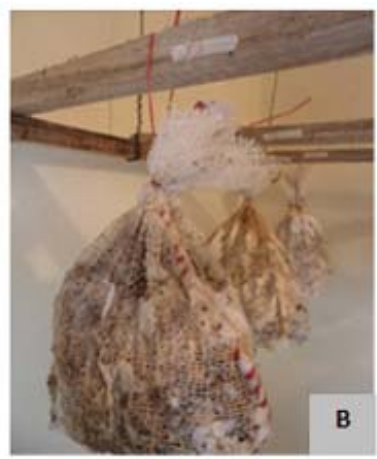

B. Colonización

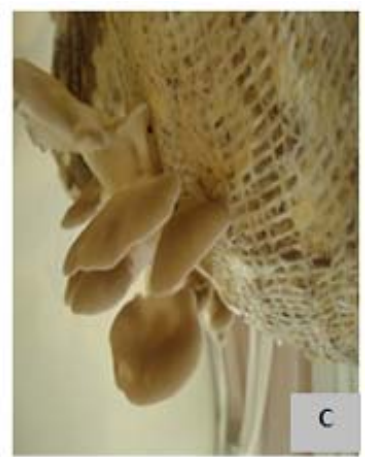

C: Producciỏn

Figura 1. Aspectos productivos de Pleurotus ostreatus.

Producción. Se obtuvieron tres cosechas, a los 24, 39 y 54 días, observándose una disminución en la cantidad de las setas producidas, las cuales fueron pesadas en una gramera para su posterior análisis.

Diámetro. Se seleccionaron cinco setas de los diferentes tratamientos y sus respectivas repeticiones, estas se midieron desde el corte del tallo hasta el borde de la oreja.

Análisis estadístico. Los resultados generados en la etapa experimental se organizaron en una matriz general en Excel. Para determinar diferencias significativas entre los tratamientos, los datos fueron procesados y analizados utilizando el software SPSS, y para las variables que mostraron diferencias estadísticamente significativas se les hizo prueba de promedios según Duncan. También se realizó análisis de frecuencia para las variables cualitativas (textura y color).

\section{RESULTADOS Y DISCUSIÓN}

Según los registros, la temperatura promedio durante la incubación fue $25,5^{\circ} \mathrm{C}$ y durante la fructificación de $22^{\circ} \mathrm{C}$. De acuerdo a la literatura, la temperatura óptima durante el tiempo de incubación es de $24-25^{\circ} \mathrm{C}$ y en la fructificación es de $18-23^{\circ} \mathrm{C}$ (Soto, 2004); indicando la favorabilidad del lugar donde se llevó a cabo la producción del hongo, presentó las condiciones de temperatura necesarias para su desarrollo.

\section{Variables físicas}

Textura de Pleurotus sp. El análisis de frecuencia muestra que todos los tratamientos tuvieron una textura carnosa, excepto el tratamiento 3 que se caracterizó por presentar textura deshidratada (Figura 2). 


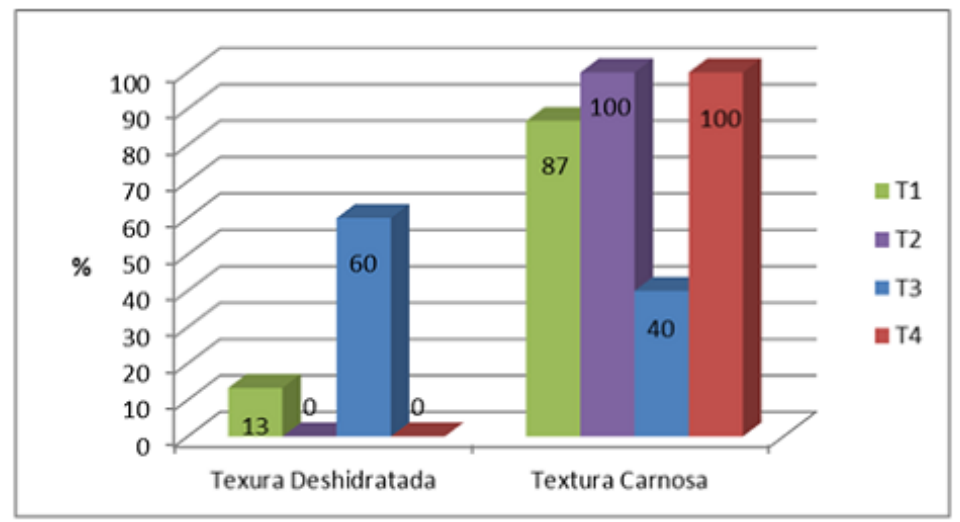

Figura 2. Textura de Pleurotus ostreatus bajo diferentes residuos orgánicos como sustrato.

Las diferencias entre la textura de los tratamientos puede deberse a que el mayor contenido de la cáscara de papa son carbohidratos solubles y no estructurales como lo requiere el hongo, ocasionando la deshidratación del mismo; teniendo en cuenta que las fructificaciones de los hongos están vivas, respirando, tomando oxígeno y desprendiendo $\mathrm{CO} 2$, degradando proteínas y carbohidratos, lo que afectará la textura y color de los mismos (Ancobe, 2011).

Color de Pleurotus sp. Los tratamientos 2 y 4 presentaron una coloración café crema, mientras que el tratamiento 1 una coloración amarillo crema, y el 3 presentó las dos coloraciones en las tres cosechas (café crema y amarillo crema) consideradas normales (Ríos, Hoyos \& Mosquera, 2010) (Figura 3).

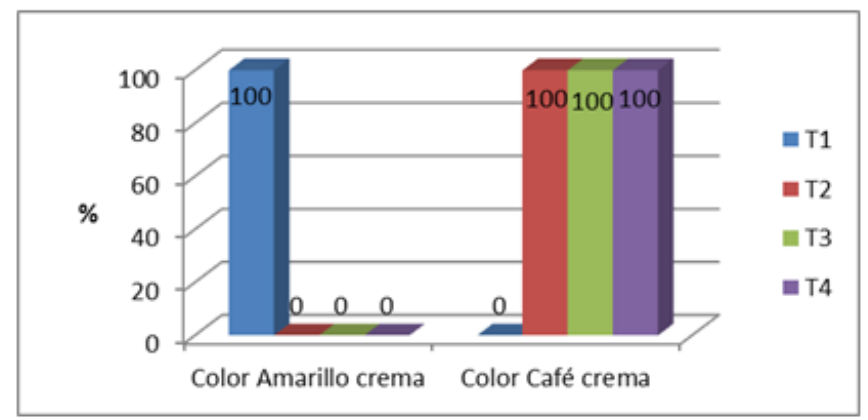

Figura 3. Color de Pleurotus ostreatus bajo diferentes residuos orgánicos como sustrato.

Conforme a lo reportado por Pérez (2006), las coloraciones de Pleurotus $\mathrm{sp}$. son blanquecinas tendientes a tomar coloraciones amarillentas, correspondiendo a los resultados encontrados para el tratamiento 1 que presentó un color amarillo cremoso (Romero, Rodríguez \& Pérez,s.f.). Los tratamientos 2, 3 y 4, presentaron un color café crema, que pudo verse relacionado con la deficiencia en la humedad del sustrato que ocasiona el oscurecimiento de la seta (Pérez, 2006); aunque Agunaga (2012) dice que Pleurotus tiene una coloración blanca tendiente al amarillamiento cuando pasa el tiempo. 


\section{Variables de Producción}

Porcentajes de colonización. El tratamiento 1 fue el de mayor porcentaje de colonización (92\%), seguido del tratamiento 2 (88,5\%), debido a que $P$. ostreatus posee una capacidad enzimática compleja que le permite degradar polímeros grandes como lignina y celulosa (Iriarte, 2003), resultados que coinciden con lo que reportan Bermúdez, García y Mourlot (2007), quienes revelan que los sustratos de mayor colonización del hongo Pleurotus ostreatus son aquellos que tienen mayor contenido de carbohidratos estructurales (lignina, celulosa y hemicelulosa), encontrados en el maíz y salvado (Ríos, Hoyos \& Mosquera, 2010;Vargas, Hoyos \& Mosquera,2012) (Figura 4).

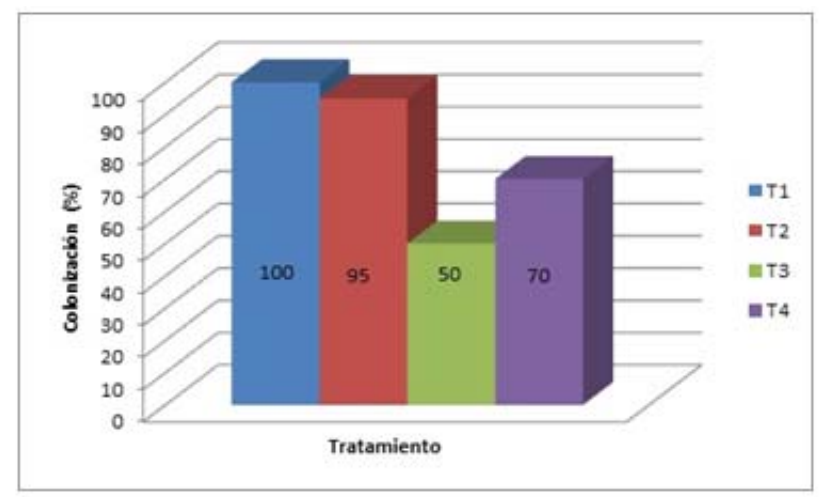

Figura 4. Porcentaje de colonización de Pleurotus ostreatus en los sustratos evaluados

Lo anterior se concuerda con lo expuesto por Okano et al. (2007) y Salmones, Mata y Waliszewski (2005), quienes sustentan que el hongo en su fase de crecimiento micelial (fase de incubación) consume preferiblemente carbohidratos solubles y hemicelulosa respecto de la celulosa y lignina. Con base en esto, los sustratos con bagazo de caña y cáscara de plátano permiten o aumentan la disponibilidad de carbohidratos solubles, compuestos fácilmente asimilables por el hongo en su fase de crecimiento micelial (Manjarrés, Castro \& Rodríguez, 2010).

\section{Producción de Pleurotus ostreatus}

EI ANOVA reveló diferencias estadísticamente significativas $(P<0,05)$, la prueba post hoc de Duncan muestra que los mejores tratamientos fueron el $1(99 \mathrm{~g})$ y $2(80,5 \mathrm{~g})$; el tratamiento demás baja productividad fue el 3 (5,8 g) (Figura 5). 


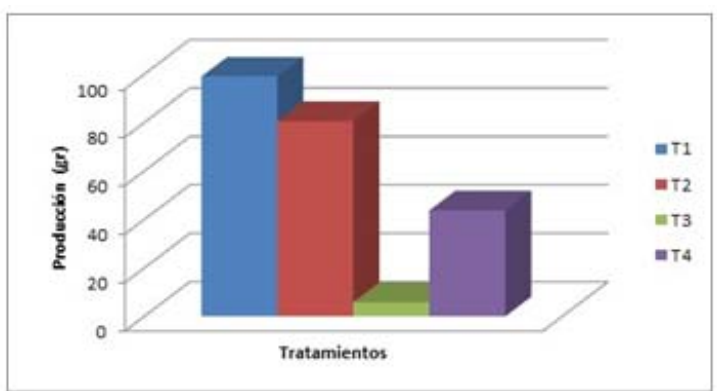

Figura 5. Producción de Pleurotus ostreatus bajo diferentes residuos orgánicos como sustrato.

Bermúdez, García y Mourlot (2007), afirman que la mayor producción se obtiene en los tratamientos donde el sustrato es rico en fibra y carbohidratos estructurales. Estos efectos se evidencia en los tratamientos 1 y 2, que tienen un alto contenido de bagazo de caña y cáscara de plátano (carbohidratos estructurales) (Medina, Martínez \& Bonilla, 2007; Choi \& Huber, 2009), que permiten el crecimiento y desarrollo del hongo y puede ser asimilado a partir de diferentes fuentes como polímeros, carbohidratos y lípidos (Iriarte, 2003).

Diámetro de Pleurotus sp. El análisis de varianza muestra diferencias estadísticas significativas, donde el tratamiento $1(4,5 \mathrm{~cm})$ expresa mejores resultados, los tratamientos 2 y 4 no presentaron diferencias, con un promedio de 3,1 cm (Figura 6).

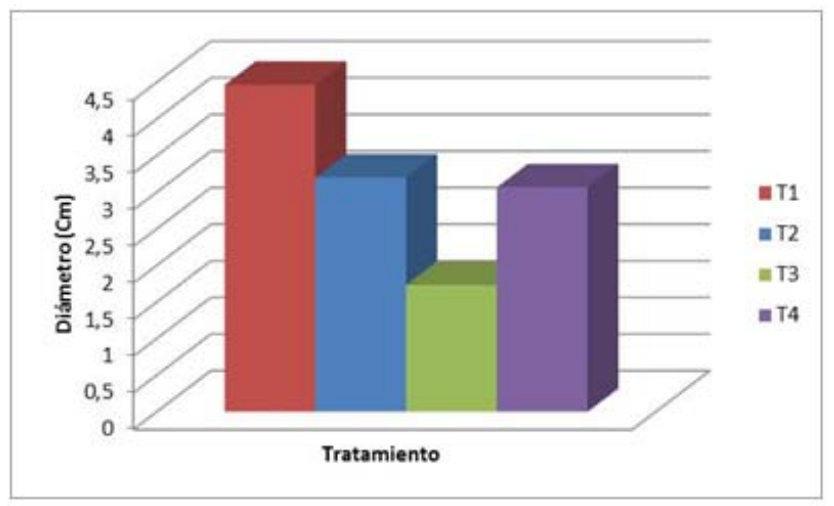

Figura 6. Diámetro de las setas de Pleurotus ostreatus bajo diferentes residuos orgánicos como sustrato.

Choiy Huber (2009), manifiestan que los residuos de plátano y papa, bajan el contenido de carbohidratos estructurales reflejándose en la baja productividad del tratamiento tres, que presento menor producción y menor diámetro de setas, pues sustituir el 37\% del contenido del sustrato por cáscara de papa, limita los nutrientes necesarios para el crecimiento del hongo; ya que este concentra mayor cantidad de almidones (García et al., 2012). Una de las mejores fuentes de carbono para el crecimiento miceliales es la celulosa, lo que indica que el sustrato del tratamiento tres carece de nutrientes suficientes para el desarrollo óptimo del hongo (Suárez, 2010). 
Pleurotus sp. es un hongo cuya fuente de alimentación se basa en carbohidratos estructurales, debido a que posee enzimas capaces de romper enlaces de estructuras complejas como lo son la lignina, la celulosa y la hemicelulosa (Liu et al., 2009); es por eso que en el presente estudio los tratamientos 1 y 2 obtuvieron los mejores resultados en cuanto a las variables productivas, pues tanto el bagazo de caña como la cáscara de plátano dentro de su composición bromatológica están constituidos en gran porcentaje por este tipo carbohidratos (Medina, Martínez \& Bonilla, 2007; Choi \& Huber, 2009), razón por la cual este tipo de sustratos (lignolíticos) empleados en la investigación, brindaron las condiciones nutricionales adecuadas para que el hongo se desarrollara; a diferencia de los tratamientos en los cuales se incluyó la cáscara de papa en los sustratos, pues este tipo de residuo está constituido por carbohidratos solubles (almidones), los cuales no son requeridos nutricionalmente por Pleurotus sp. (Choi\& Huber, 2009).

Lo anterior coincide con estudios donde los mejores resultados, están asociado a sustratos que tienen un alto contenido de lignina. Vargas et al. (2012) analizaron el bagazo de caña con aserrín de roble, obteniendo mejores resultados con el bagazo de caña. Varnero, Quiroz y Álvarez (2010) registraron mayor crecimiento del hongo en sustratos maderables, por el alto contenido de lignina. López et al. (2008) encontraron que el capacho de uchuva tuvo el mejor comportamiento de desarrollo de la seta, dado a que este material tiene un alto contenido de carbono, fuente principal de moléculas estructurales como lo es la lignina.

\section{CONCLUSIONESY RECOMENDACIONES}

La recolección de los residuos realizada en los restaurantes del corregimiento de Llacuanas, reveló que los residuos de mayor producción fueron la cáscara de plátano y papa, los cuales permitieron la elaboración del sustrato a utilizar en los cuatro tratamientos para la producción de Pleurotus ostreatus.

Los tratamientos 1 y 2, presentaron mejor comportamiento de las variables productivas, pues tanto el bagazo de caña como la cáscara de plátano dentro de su composición bromatológica están constituidos por carbohidratos estructurales que favorecen el desarrollo del hongo.

En cuanto a las variables cualitativas textura y color, las características que más se presentaron en los cuatro tratamientos fueron: textura carnosa y coloración café cremoso, respectivamente.

Se recomienda continuar con talleres de promoción del cultivo y formas de preparación de los hongos.

\section{AGRADECIMIENTOS}

Los autores agradecen al Colegio Agropecuario de LLacuanas, donde se realizó el experimento y se desarrollaron algunas recetas con los hongos producidos. A la Universidad del Cauca, por el apoyo en la investigación. 


\section{REFERENCIAS}

- Agunaga, P.N. (2012). Evaluación de cuatro sustratos para la producción del hongo ostra (Pleurotus ostreatus) en tres ciclos de producción en la zona de Tambillo, Provincia de Pichincha. Escuela Politécnica Nacional, Facultad de Ingeniería Química y Agroindustrial. Quito.

- Barros, L.; Cruz, T.; Baptista, P.; Estevinho, L.M. y Ferreira, I.C. (2008). Wild and commercial mushrooms as source of nutrients and nutraceuticals. Food Chem. Toxically., 46 (8), 2742-2747.

- Bermúdez, R; García, N. y Mourlot, A. (2007). Fermentación sólida para la producción de Pleurotus sp. sobre mezclas de pulpa de café y viruta de Cedro. Tecnología Química, 27(2), 55-62.

- Choi, S. y Donald, H. (2009). Differential sorption of 1methylcyclopropene to fruit and vegetable tissues, storage and cell wall polysaccharides, oils, and lignins. Postharvest Biology and Technology, 52(1), 62-70.

- Fernández, F. (2004). Guía práctica de producción de Setas (Pleurotus sp). Fungitec Asesorías. Guadalajara, Jalisco. México.

- García-Oduardo, N.; Bermúdez-Savón, R.C. y Serrano-Alberni, M. (2011). Formulaciones de sustratos en la producción de setas comestibles Pleurotus. Tecnología Química, XXXI (3), 15-22.

- García, S.; García, A. y Luque, J. (2012). Estudio del aprovechamiento de la cáscara de papa como insumo en la producción de alimentos balanceados para animales (Trabajo de Grado, Ingeniero de Producción Agroindustrial). Universidad de la Sabana, Facultad de Ingeniería, Programa de Producción Agroindustrial.

- Guillamón, E.; García-Lafuente, A.; Lozano, M.; D’Arrigo, M.; Rostagno, M.A.; Villares, A. y Martínez, J.A. (2010). Edible mushrooms: role in the prevention of cardiovascular diseases. Fitoterapia, 81(7), 715-723.

- Iriarte, C. (2003). Estudio de la producción y secreción de enzimas celulíticas en micelios rápidos y lentos de P. ostreatus. Navarra, España: Universidad Pública de Navarra, Ingeniería Técnico Agrícola (Hortofruticultura y Jardinería).

- Liu, L.; Lin, Z.; Zheng, T. Lin, L.; Zheng, C. et al. (2009). Fermentation optimization and characterization of the laccase from Pleurotus ostreatus strain 10969. Enzyme and MicrobialTechnology, 44(6-7), 426-433.

- López, C.; Hernández, R.; Suárez, C. y Borrero, M. (2008). Evaluación del crecimiento y producción de Pleurotus ostreatus sobre diferentes residuos agroindustriales del departamento de Cundinamarca. [en línea]. Obtenido el 4 de febrero de 2013, desde http://www.scielo.org.co/scielo.php?script=sci_arttext\&pid=S0 $12274832008000200004 \&$ Ing=en\& $n r m=i s o$

- Manjarrés, K.; Castro, A. y Rodríguez, E. (2010). Producción de la casa utilizando Pleurotus ostreatus sobre cáscaras de plátano y bagazo de caña. Revista Lasallista, 7 (2), 9-15.

- Medina, H.; Martínez, M. y Bonilla, J. (2007). Caracterización bromatológica de materias primas y subproductos en el municipio de Quibdó, Chocó. Revista Institucional Universidad Tecnológica del Chocó. Investigación, Biodiversidad y Desarrollo, 26 (2), 9-12. 
- Municipio de Almaguer. Plan de Ordenamiento Territorial de Almaguer - Cauca 2004-2016. Cali: Ediciones Feriva S.A.

- Okano, K.; Fukui, S.; Kitao, R. y Usagawa, T. (2007). Effects of culture length of Pleurotus eryngii grown on sugarcane bagasse on in vitro digestibility and chemical composition. Animal Feed Science and Technology, 136 (3- 4), 240-247.

- Pérez, B. (2006). Descripción de las características macroscópicas, de cultivo in vitro de cepas de Pleurotus aisladas en Guatemala (Trabajo degrado, Ciencias Químicas y Farmacología]. Universidad de San Carlos de Guatemala, Facultad de Ciencias Químicas y Farmacia.

- Ríos, M.; Hoyos, J.L. y Mosquera, S.A. (2010). Evaluación de los parámetros productivos de la semilla de Pleurotus ostreatus propagada en diferentes medios de cultivo. Biotecnología en el Sector Agropecuario y Agroindustrial, 8(2).

- Rodríguez, N y Jaramillo, C. (2005). Cultivo de hongos comestibles del género Pleurotus sobre residuos agrícolas de la zona cafetera, Chinchiná (Caldas): Boletín técnico N² 27.CENICAFÉ, p. 5 -52.

- Romero, J.; Rodríguez, G. y Pérez, A. (s.f.).Pleurotus ostreatus. Importancia y tecnología de cultivo. Biblioteca Virtual de las Ciencias en Cuba [en línea].Obtenido el 3 de junio de 2012, desde http://www.bibliociencias.cu/gsdl//cgi-bin/library?e=d-000-00--Orevistas--00-0-0--0prompt-10---4------0-0l--1-es-50---20-about--00031-001-1-0utfZz-8-

00\&cl=CL1.11\&d=HASH994472cca056ddf1d64128\& $=1$

- Salmones, D.; Mata, G. y Waliszewski , K.N. (2005). Comparative culturing of Pleurotus sp. on coffee pulp and wheat straw; biomass production and substrate biodegradation.Bioresour Technol., 96(5), $537-44$.

- Soto-Velazco, C. y A. Arias. (2004). El cultivo de las setas (Pleurotus spp). Tecnología de producción de alimentos. Editorial Cuellar, México. ISBN 968-5251-00-2.

- Suárez. (2010).Obtención in vitro de micelio de hongos comestibles, shiitake (lentinu laedodes) y orellanas (Pleurotus ostreatus y Pleurotus pulmonarius) a partir de aislamientos de cuerpos fructíferos, para la producción de semilla. En: Biblioteca Digital Repositorio Institucional, Bogotá D. Disponible en: http://www.bdigital.unal.edu.co/2792/

- Vargas, P.S.; Hoyos, J.L. y Mosquera, S.A. (2012). Uso de hojarasca de roble y bagazo de caña en la producción de Pleurotus ostreatus. Biotecnología en el Sector Agropecuario y Agroindustrial, 10(1), 136-145.

- Valnero, M.; Quiroz, M. y Álvarez, C. (2010). Utilización de Residuos Forestales Lignocelulósicos para Producción del Hongo Ostra (Pleurotus ostreatus). Inf. tecnol., 21(2), 13-20.

1. Artículo derivado de una investigación.

2. Ingeniera Agropecuaria, Universidad del Cauca. Grupo de Investigación Nutrición rubyleonorrivera@hotmail.com Agropecuaria.

3. Ingeniero Agropecuario, Universidad del Cauca. Candidato a Magíster en Producción Animal Tropical, Universidad Nacional de Colombia sede Palmira. Docente Catedrático Tecnología 
Agroambiental, Universidad del Valle. Grupo de Investigación Nutrición Agropecuaria. Carlosmartinez425@gmail.com

4. Ecóloga. Magíster en Recursos Hidrobiológicos. Profesora Titular, Departamento de Ciencias Agropecuarias - Ingeniería Agropecuaria, adscrita a la Facultad de Ciencias Agropecuarias y al Grupo de Investigación Nutrición Agropecuaria, Universidad del Cauca.samorales@unicauca.edu.co

Para citar este artículo: Rivera-Omen, R. L., Martínez-Mamián, C. A. \& Morales-Velasco, S. (2013). Evaluación de residuos agrícolas como sustrato para la producción de Pleurotus ostreatus. Revista Luna Azul, 37, 89-100. Recuperado de http://lunazul.ucaldas.edu.co/index.php?option=content\&task=view\&id=847 